\title{
Elementos sociohistóricos para entender la migración haitiana a República Dominicana
}

\section{Sociohistorical elements to understand Haitian migration to the Dominican Republic}

\author{
Schwarz Coulange-Méroné
}

\author{
Centro de Estudios Demográficos, Urbanos y Ambientales \\ El Colegio de México, Ciudad de México, México
}

Resumen

Uno de los rasgos más destacados de la demografía del mercado de trabajo de República Dominicana a lo largo de los últimos cien años es la presencia de un número significativo de trabajadores haitianos y dominicanos de ascendencia haitiana. Desde que la mano de obra haitiana empezó a ingresar el mercado laboral dominicano tras el despegue de la industria azucarera de este país el flujo migratorio no se ha detenido; esto, pese a las vicisitudes que los migrantes y, posteriormente sus hijos nacidos en República Dominicana han experimentado a través de las décadas. En este artículo, se presenta la evolución de este flujo migratorio resaltando tres periodos distintos que, desde nuestro punto de vista han estructurado esta migración.

Palabras clave: Migración, industria azucarera, mercado laboral, inmigrantes haitianos.

Abstract

One of the most outstanding features of the demography of the Dominican Republic's labor market over the last hundred years is the presence of a considerable number of Haitian and Dominican of Haitian descent workers. Since Haitian workers began to enter this market after the notable boom of the Dominican sugar industry, the flow of migrants has never stopped, despite the vicissitudes that themselves and later their children born in the Dominican Republic have experienced. In this article, I offer a historical overview of Haitian labor migration to the Dominican Republic, considering three periods that, from my point of view, have structured this migratory flow.

Key words: Migration, sugar industry, labor market, Haitian immigrants. 


\section{INTRODUCCIÓN}

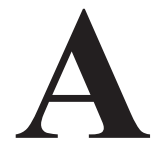

pesar de sus diferencias y pese a la existencia de grupos en ambos países que apuestan por lo contrario, Haití y República Dominicana están vinculados por realidades antiguas y arraigadas que sin duda serán difíciles y quizá imposibles deconstruir a corto o mediano plazo. ${ }^{1}$ Una de esas realidades es la presencia de una densa y consolidada población de origen haitiano que resulta de cien años de migración desde Haití hacia República Dominicana. Si bien esta migración surgió como parte de un proceso económico en el que participaron diferentes países y territorios del Caribe, se consolidó y se complejizó a lo largo de las décadas convirtiéndose prácticamente en una manzana de la discordia entre los dos países (Alexandre, 2012).

En los últimos años, la migración haitiana a República Dominicana se ha hecho conocida internacionalmente por las condiciones esclavizantes en que se encuentra un número importante de haitianos y dominico-haitianos en los bateyes, ${ }^{2}$ así como episodios de crisis en torno a ella. Para aquéllos que no están familiarizados con el tema, puede resultar difícil entender esta migración y sobre todo los eventos que la han marcado en periodos recientes desde una perspectiva que va más allá de lo coyuntural.

Considerando lo anterior, en este artículo se ofrece un recorrido a través de la historia de esta migración, especialmente su componente laboral, exponiendo algunas de las fuerzas que la han impulsado a lo largo de sus cien años de antigüedad. Se presta atención a tres periodos distintos que, desde nuestro punto de vista, representan contextos sociohistóricos particulares en los que han surgido fuerzas diferentes que han asegurado la continuidad de la migración. El artículo está dividido en tres secciones correspondiendo a los tres periodos a los que se hace referencia. La primera sección aborda el periodo de inicio de la migración (1910-1930); en la segunda, se presenta el periodo de maduración de la mano de obra haitiana en el mercado laboral dominicano especialmente en la industria azucarera (19301975). En la última sección, se aborda la diversificación de las actividades laborales de los migrantes haitianos (desde mediados de los setenta hasta

${ }^{1}$ Los dos países comparten una misma isla (La Española), una parte de sus historias respectivas, relaciones comerciales importantes aunque casi unidireccionales - de República Dominicana hacia Haití-, una antigua y vigorosa corriente migratoria, entre otros vínculos.

${ }^{2}$ Grosso modo, los bateyes son los espacios de cultivo y transformación de la caña de azúcar. 
nuestros días). En cada periodo, tratamos de identificar las fuerzas que sostuvieron la migración y las continuidades que permiten entender en buena medida situaciones actuales desde una perspectiva más amplia.

\section{0-1920: INICIO de LA MIGRACIÓN HAITIANA}

\section{a República Dominicana}

Aunque los movimientos de personas entre Haití y República Dominicana se remontan a periodos lejanos (Moral, 1978), existe un consenso entre los estudiosos del tema para fechar el inicio de la migración haitiana contemporánea a este país en la segunda década del siglo XX (Manigat, 2012; Lozano y Báez, 2011; Wooding y Moseley-Williams, 2004). Este consenso se fundamenta en que este flujo migratorio que surgió a partir de ese periodo como respuesta a una serie de procesos económicos, políticos y sociales propios de cada uno de los dos países ha permanecido a pesar de los altibajos y transformaciones que ha sufrido a lo largo de las décadas. En otras palabras, es posible narrar de forma continua y coherente la migración haitiana a República Dominicana empezando con los movimientos migratorios ocurridos desde aquella época.

Uno de los procesos referidos fue la expansión de la industria azucarera dominicana entre finales del siglo XIX y comienzos del XX. Esa expansión se sustentó en un contexto internacional particularmente favorable ${ }^{3}$ del que República Dominicana ${ }^{4}$ y otros países del Caribe —en particular Cuba y Puerto Rico - lograron aprovechar (Castillo, 2005; Wooding y Moseley-Williams, 2004). En efecto, en esa época, el capital estadounidense empezó a realizar inversiones considerables en el sector cañero en el Caribe con el fin de competir con los productores europeos de azúcar de remolacha — principalmente Francia y Alemania — y luego, para aprovechar que los mismos estaban envueltos en acontecimientos bélicas (Castillo, 2005; Domenach, 1986; Castor,1983). En República Dominicana, las in-

\footnotetext{
${ }^{3}$ Diversos acontecimientos bélicos internacionales ocurridos a finales del siglo XIX contribuyeron a explicar el desarrollo de la industria azucarera dominicana (Castillo, 2005). Dentro de ellos se destacan la Guerra de Secesión en Estados Unidos (1861-1865) que impactó negativamente el sector cañero en Luisiana, la Guerra de los Diez años en Cuba (1868-1878) que tuvo efectos perjudiciales al entonces principal exportador mundial de azúcar, lo cual empujó un grupo de empresarios y técnicos cañeros cubanos hacia República Dominicana, la Guerra francoalemana de 1878 que afectó los dos principales productores europeos de azúcar de remolacha (Francia y Alemania). Esos eventos incentivaron a empresarios azucareros a buscar lugares cuya estabilidad y condiciones climáticas les permitieran obtener mayores beneficios.

${ }^{4}$ El país ofreció condiciones de estabilidad política, tierra barata, las condiciones naturales favorables, así como leyes y medidas incentivadoras a los inversionistas del sector cañero. Además, la firma de un Tratado de libre Comercio entre Estados Unidos y República Dominicana (1884) para la exportación del azúcar dominicano contribuyó a crear un contexto propicio a la expansión de la industria azucarera en este país.
} 
versiones estadounidenses ayudaron a extender el sector azucarero que ya había venido modernizándose desde el último cuarto del siglo XIX con la llegada de un grupo de empresarios y técnicos cañeros cubanos que habían huido de la Guerra de los Diez Años en su país (Castillo, 2005).

Contrariamente a República Dominicana, y pese a que, en tiempos previos, fue uno de los principales productores de azúcar regional y mundialmente, Haití no se encontró entre los destinatarios de las inversiones ya que una serie de barreras estructurales $\mathrm{y}$ coyunturales impidieron la penetración del capital extranjero. ${ }^{5}$ Como consuelo, conjuntamente con otras islas de la región — Jamaica, San Cristóbal, San Vicente y otras caribeñas, formando la llamada migración cocola - Haití se insertó en la nueva economía cañera regional como proveedor de mano de obra, pues los países sedes de las instalaciones industriales carecieron de suficientes trabajadores para realizar la totalidad de las labores que demandó el desarrollo del sector (Wooding y MoseleyWilliams, 2004; Tejada, 2001; Castillo, 1978). ${ }^{6}$

A diferencia de lo que sucedería con la migración cocola años después — hablaremos de eso más adelante-, este proceso económico tendría una influencia fundamental sobre la dinámica migratoria entre Haití y República Dominicana, así como la composición sociodemográfica (hombres, jóvenes, campesinos, personas con bajos niveles de escolaridad) y la procedencia regional de los migrantes haitianos (Méroné, 2017). Durante la mayor parte del siglo XX, es la dinámica de la industria azucarera — con los periodos de zafra y de tiempos muertos ${ }^{7}$ así como sus fluctuaciones de un año al otro- la que determinaría esencialmente las cantidades de trabajadores haitianos que migrarían a República Dominicana. La relación entre este sector y la migración haitiana a

\footnotetext{
${ }^{5}$ Con respecto a las barreras estructurales, la cuestión de la tenencia de la tierra puede considerarse como la principal. Desde la emancipación política de Haití (1804), no se había resuelto ese problema; al contrario, empeoró conforme pasaban las décadas con la fragmentación de la tierra (Moral, 1978). Además, hasta el año 1918, se había prohibido constitucionalmente a los extranjeros el derecho de propiedad de tierra; una medida que, si bien buscaba garantizar la consolidación de la independencia del país, dificultó la inversión extranjera a gran escala (Castor, 1983; Moral, 1978). En cuanto a factores coyunturales, se trata principalmente de la inestabilidad política que caracterizó buena parte del siglo XIX y principios del XX en ese país (Castor, 1971).

${ }^{6}$ En el caso de República Dominicana, algunos autores señalan que la falta de mano de obra también se debió a que, ya a partir de finales del siglo XIX, los trabajadores campesinos empezaron a evadir el sector cañero a causa de los bajos salarios que se pagaban (Castillo, 2005, 1978; Tejada, 2001). Para suplir la escasez de mano de obra generada por esa situación, los empresarios se dirigieron primero hacía las islas vecinas y luego hacia Haití.

${ }^{7}$ La zafra se refiere al periodo de cosecha de la caña y los procesos manuales e industriales que llevan a su transformación en azúcar. Es durante ese periodo que se emplea la mayor cantidad de trabajadores. En cambio, el tiempo muerto corresponde al periodo de maduración de la caña. En general, solo se requiere una cantidad limitada de trabajadores durante el tiempo muerto.
} 
este país es tan estrecha que buena parte de la historia de ésta, especialmente la laboral, es parte de la propia historia de la industria azucarera.

Por otra parte, hay que traer a colación el factor geopolítico en los causantes del inicio de la migración haitiana a República Dominicana: la ocupación militar simultánea de los dos países por Estados Unidos (1915-1934 en Haití y 1916-1924 en República Dominicana). En Haití, una de las expresiones de la ocupación fue la implantación a gran escala de empresas agrícolas estadounidenses, ${ }^{8}$ sobre todo en la producción de frutas (Gaillard, 1981; Moral, 1978; Castor, 1971). Para ello, miles de campesinos fueron despojados de las tierras que ocupaban en diversas zonas del país. Esa política, junto con otras medidas a expensas de los campesinos, desató una guerrilla rural contra el ocupante. Para librarse de las revueltas y deshacerse del excedente de población agrícola, la administración militar impulsó la salida de campesinos haitianos hacia los ingenios azucareros de República Dominicana y Cuba (Riveros, 2014; Castor, 1983).

En conjunto, lo anterior apunta a que el inicio de la migración laboral haitiana a República Dominicana se produjo en el marco de un proyecto en que los Estados y las sociedades dominicana y haitiana no eran los principales protagonistas. Al contrario, en su inicio, la migración haitiana provocó inquietudes en los dos países. ${ }^{9}$ Por ejemplo, Martínez (1999) señala que en República Dominicana hubo grupos de trabajadores que se organizaron en contra de la inmigración extranjera - esencialmente la haitiana y la cocola - ya que, desde su punto de vista, es la causa de la disminución de los salarios en el sector cañero. Por su parte, miembros de las élites dominicanas de la época expresaron

\footnotetext{
${ }^{8}$ La administración militar estadounidense había levantado el recurrente bloqueo constitucional sobre la propiedad de extranjeros mencionado anteriormente. El quinto artículo de la constitución de 1918 - adoptada durante la ocupación- ratificó esa decisión (Véase Gaillard, 1981; Moral, 1978 y Castor, 1971).

${ }^{9}$ En Haití, por ejemplo, en marzo de 1916, el periódico Le Nouvelliste, citado por Gaillard (1981: 213), denunció "el abandono del suelo nacional por volúmenes importantes de campesinos, llamando al gobierno haitiano a investigar este asunto a la brevedad". Al año siguiente, un exdiplomático, Vilius Gervais, declaró en el mismo periódico: "ya no se trata de un éxodo sencillo sino el despoblamiento continuo de nuestro campo" (Gaillard, 1981: 124). Asimismo, de acuerdo con Moral (1978), los nacionalistas denunciaron una fuga continua de la mano de obra rural. En cuanto al gobierno haitiano, aunque subordinado a la administración ocupante estadounidense, creó un impuesto sobre la emigración, luego aumentó los costos de adquisición del pasaporte y buscó controlar las compañías de reclutamiento de trabajadores nacionales para los ingenios de Cuba y República Dominicana. En 1928, llegó hasta prohibir la emigración. Pero ninguna de esas medidas logró contrarrestar la emigración; pues, además del deterioro de las condiciones de vida de los campesinos, las medidas incitativas a la emigración adoptadas por la administración militar estaban vigentes y los representantes de los ingenios -instalados en diversas zonas del país - continuaban con su labor de reclutamiento de mano de obra (véase Moral, 1978: 59-71).
} 
temores de que la industria del azúcar se convirtiera en un sector completamente en manos de extranjeros, tanto por el origen del capital invertido como por los trabajadores que la hacían funcionar (Martínez, 1999).

A nivel político-institucional, en 1912, el congreso dominicano adoptó una ley que prohibió la entrada de inmigrantes "de raza que no sea la caucasiana (sic)" para trabajar en la agricultura (Martínez, 1999; Castillo, 1978). De acuerdo con esa ley, esa inmigración podría realizarse sólo cuando se comprobara que la cosecha del año corriera algún peligro por falta de braceros (Castillo, 1978). ${ }^{10}$ Sin embargo, debido a los poderosos intereses que estaban en juego en esa inmigración, y la ocupación simultánea de los dos países, esa ley tuvo muy poca aplicación; pues, los números de trabajadores haitianos y otros caribeños de "raza no caucásica" siguieron creciendo en años posteriores a su adopción (Tejada, 2001; Baud, 1993; Castillo, 1978).

A pesar de las preocupaciones expresadas en diferentes niveles en los dos países, la migración no se detuvo. Al contrario, siguió aumentando de tal manera que, durante la década de los veinte del siglo XX, los trabajadores haitianos llegaron a desplazar la mano de obra cocola del mercado de trabajo azucarero (Castillo, 1978). Aunque es difícil establecer con exactitud los números de trabajadores haitianos que laboraron en República Dominicana durante la época, el censo de 1920 indica que ya para este año, los inmigrantes haitianos - incluyendo a los que se dedicaban a otras actividades y aquellos que no trabajaban - representaban el mayor grupo de extranjeros en este país (28,258 personas). El segundo grupo de no nacionales de República Dominicana en importancia numérica, los puertorriqueños, solo contaba con 6,069 personas.

También, este censo revela algunas tendencias claves sobre los haitianos en la época. Por ejemplo, los datos de ese censo indican que hasta 1920 la migración era principalmente de proximidad ya que 71 por ciento de los haitianos se concentraban en provincias limítrofes o cercanas a la frontera como son Monte Cristi, Barahona y Azua. ${ }^{11}$ Esta distribución espacial sugiere que los haitianos no se dedicaban exclusivamente a actividades relacionadas a la industria azucarera; de hecho, con excepción de Barahona, las otras dos provincias no formaban parte de los emplazamientos de los cañaverales en la época (Figura 1).

\footnotetext{
${ }^{10}$ De acuerdo con Castillo (1978), el tercer artículo de dicha ley establece: "Necesitan previo permiso para inmigrar al país los naturales de las colonias europeas en América, los de Asia, los de África y los de Oceanía, así como los braceros de otra raza que no sea la caucasiana. El permiso será solicitado del Poder Ejecutivo, quien deberá negarlo cada vez que no esté convencido de la utilidad general del inmigrante (...)"

${ }^{11}$ Cálculos propios realizados con datos del censo de 1920 publicado por Castillo (1978).
} 
Elementos sociohistoricos para entender la migración haitiana a Repüblica Dominicana / S. COULANGE MÉRONÉ

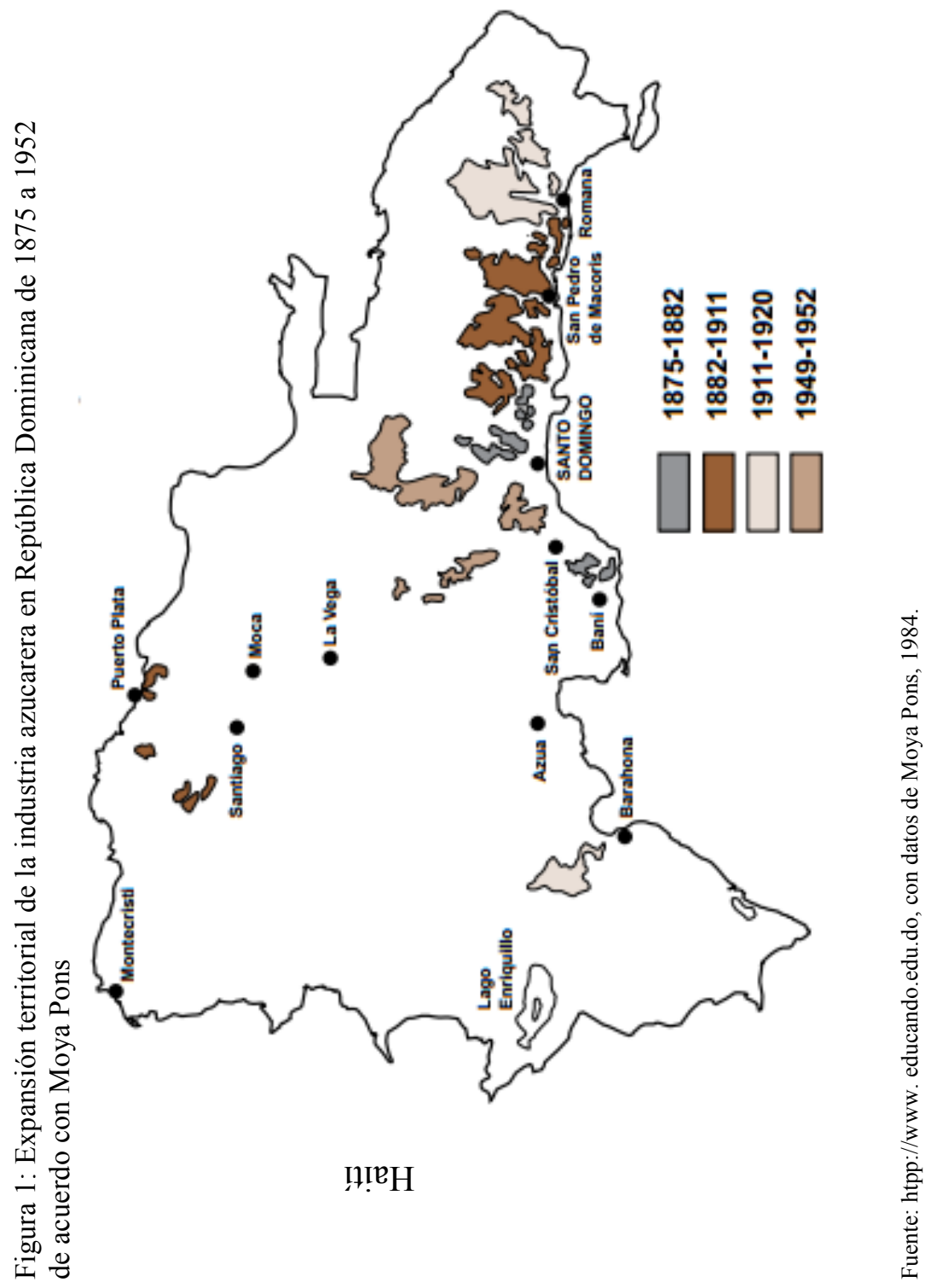


Esto es coherente con una tendencia ya observada desde años antes, a saber que muchos campesinos haitianos tendían a pasar al territorio dominicano para establecerse en terrenos despoblados de la región fronteriza (Moral, 1978).

Esas personas se dedicaban a otros cultivos y a actividades no agrícolas (Castor, 1983). Otra información que reveló el censo de 1920 es que, aun siendo el grupo de extranjeros numéricamente mayoritario a nivel nacional, los haitianos no ocupaban esta posición en provincias cañeras como San Pedro de Macorís o Santo Domingo, sino la segunda - después de los cocolos y los puertorriqueños. Es decir, hasta 1920, la mano de obra haitiana aun no era preponderante en la industria azucarera dominicana, aunque ya era significativa.

Sin embargo, el predominio de los trabajadores haitianos no tardaría en materializarse ya que durante la década de los veinte desplazarían a los cocolos. De acuerdo con Castillo (1978), durante ese periodo, la proporción de braceros cocolos fue disminuyendo debido a que las empresas azucareras recurrieron cada vez a más braceros haitianos. En un contexto depresivo en que cayó el precio del azúcar a nivel internacional, ${ }^{12}$ dichas empresas encontraban en el haitiano una fuerza de trabajo más barata que la cocola. Se calcula que, en 1925, un número de 100 mil haitianos se encontraba viviendo en República Dominicana (Castor, 1983). El Departamento de Estado de Estados Unidos apoya esta estimación al señalar en un informe, en 1926, que: "la penetración a través de la frontera (con Haití) es constante y la cantidad al presente se sabe que es superior a los 60 mil, y quizás alcance los 100 mil haitianos, como se cita en García Muñiz, 2005”. Otra fuente estima que en los años veinte había "unos cuatro extranjeros de origen (sic) por cada dominicano en todos los aspectos relacionados a la plantación como se cita en García Muñiz, 2005".

Cabe señalar que esta transición tuvo lugar en un contexto en que la industria azucarera dominicana pasó a ser controlada mayoritariamente por el capital estadunidense (Castillo, 2005). ${ }^{13}$ En un contexto en que Haití y República Dominicana se encontraban bajo la ocupación militar de Estados Unidos, las diferentes órdenes ejecutivas de la administración militar

\footnotetext{
${ }^{12}$ Tras la Primera Guerra Mundial, a partir de 1920, los productores europeos de azúcar de remolacha (principalmente Francia y Alemania) se recuperaron y reingresaron el mercado mundial provocando la caída drástica de los precios a nivel internacional (Castillo, 2005).

${ }_{13}$ En 1925, entre los 22 ingenios existentes, 12 eran propiedad de compañías estadounidenses, pero representaron 81 por ciento de los terrenos ocupados por los cultivos de caña de azúcar, y 82 por ciento del capital declarado. Solo tres de los ingenios estadounidenses aportaban casi la mitad de la producción azucarera dominicana correspondiente a la zafra 1925-26 (Castillo, 2005: 69).
} 
respecto a la migración tendían a apoyar la demanda en mano de obra de las empresas estadounidenses. En efecto, esas decisiones se encaminaban a fomentar la migración haitiana hacia los ingenios ubicados en el territorio dominicano en el marco de lo que Wilfredo Lozano denomina el modelo de mercado laboral insular abierto (Lozano, 2005), mismo que garantizó la disponibilidad de mano de obra barata para las empresas azucareras y, al mismo tiempo, aliviar las revueltas campesinas en contra de la ocupación estadounidense en Haití. Hacia el horizonte de 1930, las nuevas oportunidades de empleo en otras partes del Caribe (las plantas petroleras en las Antillas holandesas, por ejemplo) acabaron con la migración cocola a República Dominicana abriendo, por lo tanto, la era de la dependencia de la industria azucarera dominicana de la mano de obra haitiana.

\section{0-1975: CONSOLIDACIÓN DE LA MANO DE OBRA HAITIANA en República Dominicana}

Durante la década de los treinta, se confirmó el predominio de la mano de obra haitiana en diversas labores no calificadas de la industria azucarera dominicana de tal forma que en 1935 los haitianos formaban las cinco sextas partes del conjunto de trabajadores de los ingenios (Castor, 1983). Esto, debido a que, por un lado, los mecanismos sociales de expulsión (pauperización del campesinado haitiano, Moral, 1978) y atracción (preferencia por la mano de obra haitiana por parte de los empresarios azucareros, Vega, 1988) se mantuvieron vigentes. Por otro lado, la consolidación de la mano de obra haitiana en el sector azucarero dominicano estuvo relacionada con la reacción de Cuba frente a la crisis económica de los años treinta. Como se sabe, la depresión de los años treinta impactó fuertemente la economía estadounidense y las que gravitaban sobre su eje como era el caso de las latinoamericanas y caribeñas. Precisamente, "la economía cubana fue una de las más afectadas por el episodio depresivo como se cita en Santamaría, (1995)" razón por la cual este país decidió adoptar medidas restrictivas para contener la migración haitiana y de otras islas vecinas (Castor, 1983; Moral, 1978). Durante la década de los años treinta, alrededor de 70 mil trabajadores haitianos fueron expulsados de Cuba, mismos que volvieron a emigrar masivamente a República Dominicana, ya que no encontraron políticas de reinserción laboral en su país, contribuyendo a engrosar el número de trabajadores de origen haitiano (Tejada, 2001; Báez, 1986; Castor, 1983).

Cabe señalar también que, además de la migración hacia los ingenios azucareros, también seguía floreciendo la de proximidad, es decir la que 
se dirigía hacia las zonas cercanas a la frontera —oficialmente establecida en 1936. "En ciertos pueblos (fronterizos), algunas ramas de actividades tales como la hojalatería y la mecánica de automóviles eran ejercidas exclusivamente por haitianos. (También) llegaron a controlar casi toda la producción de maní en la zona" (Castor, 1983). Con esas dinámicas, no es sorprendente pues que fuentes oficiales como el censo de 1935 registraran aumentos considerables en los números de nacionales de Haití que vivían en República Dominicana en comparación con años previos. ${ }^{14}$

Ese crecimiento de la migración haitiana se dio en paralelo con las controversias y negociaciones en torno a la delimitación de la frontera entre los dos países, la cual se resolvió en 1936 con la firma por ambas naciones del Protocolo de Revisión del Tratado sobre la fijación de la frontera de 1929. Sin embargo, el trazado de la frontera sería, según varios autores, una de las causas principales de la matanza de miles ${ }^{15}$ de inmigrantes haitianos y sus hijos en 1937 durante el régimen del dictador Trujillo (Turits, 2014; Derby y Turits, 1993; Moya Pons, 1992; Castor, 1983; Price Mars, 1953). Según estos autores, el trazado de la línea divisoria de la isla dejaba a varios poblados de haitianos en territorio dominicano. El resultado fue que una buena porción de la parte dominicana de la región fronteriza quedaba como una franja "culturalmente haitiana". Esta situación fue percibida como un peligro para la soberanía y la identidad de República Dominicana en un momento en que la población dominicana no rebasaba un millón y medio frente a la población residente en Haití que ya contaba tres millones de personas (Castor, 1983). En opinión de varios autores, el dictador Rafael Trujillo adoptó el llamado plan de dominicanización de la parte dominicana de la zona fronteriza para eliminar las comunidades haitianas y reemplazarlas por dominicanos e inmigrantes blancos procedentes de otros países (Moya Pons, 1992; Vega, 1988; Castor, 1983).

Es sugerente notar que la masacre tuvo lugar en la zona fronteriza y en localidades de la llamada línea noroeste (Vega, 1988), es decir, lejos de las zonas cañeras que se encontraban esencialmente en el este y sureste del país (ver Figura 1). Como se vio anteriormente, la industria del azúcar

\footnotetext{
${ }^{14}$ Según datos del censo de 1935 un número de 52,657 haitianos residían en situación regular en República Dominicana (Castor, 1983: 57). El censo no proporcionó datos sobre aquéllos que vivían de forma irregular en el país. Es probable que ese número se encontrase muy por debajo de las cifras totales ya que, como se vio anteriormente, desde 1925 alrededor de 100 mil haitianos vivían en situaciones regulares e irregulares en el país. Aun así, la cifra censal de 1935 representa casi el doble de lo que registraba el censo anterior, es decir el de 1920 (28,258 personas).

${ }^{15}$ Existen diferentes cifras sobre la cantidad de personas asesinadas en esos acontecimientos que varían desde "varios cientos" hasta 35 mil personas. Bernardo Vega (1988), por ejemplo, ofrece 54 estimaciones distintas publicadas sobre el número de personas asesinadas durante los acontecimientos de 1937.
} 
ya dependía de la mano de obra haitiana para las tareas no calificadas pero esenciales. La disponibilidad de los trabajadores haitianos era vital para su continuidad y su desarrollo. Dos años después de la matanza, se adoptó la ley de inmigración que, aunque restringió la inmigración de "personas de raza no caucásica o americana autóctona", permitió la entrada de jornaleros temporales "cuando soliciten su introducción las empresas agrícolas (...) para llenar las necesidades de tales empresas" (Artículo 3, Ley de inmigración del 14 de abril del 1939).

Sin embargo, la realidad fue que el ingreso clandestino de trabajadores haitianos siguió su curso bajo el impulso de las compañías azucareras y la complicidad de las autoridades haitianas y dominicanas. De acuerdo con la historiadora haitiana Suzy Castor, "una ruta especial a través de la frontera, por el Morne des Commissaires, ${ }^{16}$ permitía la entrada de miles de haitianos y camiones militares aseguraban su traslado desde la frontera hasta los ingenios. Este tráfico se apoyaba en Haití sobre una red de altos funcionarios, de pequeños y grandes burgueses y aun de algunos fugados de la gehena, los viejos ex-braceros que según la fórmula legendaria se han constituido en vendedores de sus hermanos mal informados como se cita en Corten, 1971".

Durante las décadas de los cuarenta y cincuenta, se constituyó el imperio azucarero de Trujillo después de que comprara la mayor parte de los ingenios de capital estadounidense y la fundación de otros nuevos dando un nuevo impulso a la demanda de mano de obra (Cuello, 1997). En 1952, el gobierno de Trujillo inició la firma de una serie de acuerdos con el gobierno haitiano para la contratación de trabajadores temporales. Tres acuerdos fueron firmados por un periodo de cinco años cada uno - el 5 de enero de 1952, el 21 de diciembre de 1959 y el 14 de noviembre de 1966. A partir de 1971, fue el Consejo Estatal del Azúcar (CEA) ${ }^{17}$ el que se encargó de la negociación y firma de los acuerdos por la parte dominicana. Autores como Bernardo Vega (1983) señalan que, a partir de ese año, los acuerdos eran ilegales debido que el CEA no estaba habilitado para llevar a cabo una negociación internacional. No obstante, los acuerdos firmados por el CEA y el gobierno haitiano funcionaron hasta 1986. Estos acuerdos sirvieron de marco jurídico a la contratación, la transportación, el trabajo, el asentamiento y la repatriación de trabajadores temporales haitianos hasta 1986.

Sin embargo, al margen de los acuerdos señalados, la "industria" de la clandestinidad siguió funcionando, alimentando la migración de trabaja-

\footnotetext{
${ }^{16}$ Precisamente en el sureste de Haití, región donde se originó buena parte de los braceros.

${ }^{17}$ El Consejo Estatal del Azúcar (CEA), creado en 1966, es el organismo del Estado dominicano que recuperó el imperio azucarero de Trujillo tras su asesinato en 1961.
} 
dores y su permanencia en República Dominicana (Manigat, 1997). Según estimaciones de Wilfredo Lozano, un promedio de 25 mil braceros haitianos ingresó a República Dominicana anualmente entre 1967 y 1980, de los cuales a veces más de la mitad lo hizo al margen de la legalidad (Lozano, 2005). Ante la falta de información sobre los años posteriores, Lozano (2005) basándose en las estimaciones de deportaciones durante la década de los noventa y principios de los dos mil plantea la hipótesis de que, en ese periodo, alrededor de 20 mil haitianos ingresaron a República Dominicana anualmente, de forma irregular en su mayoría.

\section{5- hasta NUESTROS díAs: DiVERSIFICACión de LA ACTIVIDAD LABORAL DE LA POBLACIÓN DE ORIGEN HAITIANO}

Si bien la migración haitiana a República Dominicana estuvo predominantemente vinculada con la industria azucarera durante buena parte del siglo XX, a partir de mediados de los años setenta se empezó a observar la penetración significativa de trabajadores haitianos en sectores agrícolas no cañeros, tales como el café, el arroz, el tabaco, entre otros (Lozano, 1998). En realidad, la presencia de la mano de obra haitiana en la agricultura no azucarera era conocida desde mucho antes, ya que era costumbre que los haitianos fueran a trabajar en otros cultivos, especialmente el café, durante el periodo de tiempo muerto en la industria del azúcar (Lozano, 2005, 1998; Báez, 1986). Sin embargo, esta tendencia empezó a generalizarse a partir del declive de la industria azucarera iniciado en los años setenta.

A partir de ese periodo, debido a una serie de factores, en particular, la caída de los precios del azúcar a nivel internacional, el desarrollo de técnicas para extraer azúcar del maíz, la competencia de países productores de azúcar como India y Brasil, entre otros, el sector azucarero dominicano empezó a presentar síntomas de crisis. Una señal importante de las dificultades que prevalecían en el sector fue que, a principios de los ochenta, dos ingenios cesaron sus actividades. A partir de 1988, el CEA redujo su producción a 50 por ciento sin lograr detener el deterioro. La producción de azúcar morena que alcanzó 651,685 toneladas métricas en 1980 cayó a 189,594 toneladas en 1999 (Rubens, 2010). A finales de los años noventa, las autoridades decidieron privatizar la mayor parte de los ingenios estatales administrados por el CEA, pero tampoco se obtuvo la revitalización de la industria. Hoy en día, la mayoría de los ingenios estatales y privados están cerrados o desmantelados. Ante estos cambios, se redujeron las áreas sembradas de caña provocando la salida del excedente de mano de obra hacia otros cultivos u otras actividades (Lozano, 2005). 
Durante los años ochenta, la crisis agraria expandió al resto de la agricultura dominicana agravando la situación de los productores rurales dominicanos quienes migraron en cantidades significativas hacia las ciudades u a otros países, especialmente Estados Unidos (Lozano, 2005, 1998). Ese éxodo acentuó la escasez de mano de obra nativa en cultivos como el café, el arroz y el maíz, y favoreció la entrada de trabajadores haitianos (Báez y Lozano, 1985). En 1980, por ejemplo, la Oficina Nacional de Planificación (ONAPLAN) estimó que 28.6 por ciento de los trabajadores en la cosecha del café para ese año eran haitianos. A mediados de los años ochenta, Báez y Lozano (1985) estimaron que 54 por ciento de los jornaleros en el café, y 19 por ciento de aquéllos que laboraban en la producción arrocera eran de origen haitiano. De igual forma, la presencia de trabajadores de origen haitiano en cultivos tales como plátano, piña, tomate, tabaco y otros aumentó durante las décadas de los ochenta, noventa y dos mil de una manera tal que hoy en día representan una mano de obra vital para la producción de estos productos (Lozano, 2005).

Los cambios en el sector agrícola ocurrieron en un contexto más amplio de diversificación económica iniciada a finales de los sesenta (Ariza, 2004). A partir de esa época, comenzó la tercerización de la economía dominicana especialmente con el desarrollo de sectores como las zonas francas de exportación ${ }^{18}$ y los servicios. Los datos de la Figura 2 ilustran la decadencia que experimentó el sector agropecuario (en el cual está clasificada la industria azucarera) de 1960 a 2015. Según estos datos, mientras el sector agropecuario captaba 60 por ciento de la población ocupada en 1960, soló empleaba 13.4 por ciento en 2015. En cambio, el sector de los servicios ha experimentado aumentos significativos en su atracción de la población ocupada; en 2015, siete de cada diez trabajadores laboraban en los servicios (69.5 por ciento) mientras que en 1960 apenas alcanzaba 25 por ciento. Lo mismo puede decirse para el sector industrial que pasó de ocupar 11.4 por ciento de la población ocupada en 1960 a emplear 25.4 por ciento de la misma en 1999, pero luego bajó en importancia captando 17.2 por ciento de la mano de obra total en 2015.

En cuanto a Haití, durante el mismo periodo, ha experimentado otros procesos políticos, económicos, sociales y ambientales, que contribuyeron a aumentar el volumen y diversificar el origen social de los migrantes que van tanto a República Dominicana como a otros destinos. Por ejemplo, entre finales de los setenta y principios de los ochenta, a causa de la pre-

${ }^{18}$ El número de zonas francas en República Dominicana pasó de uno en 1969 a 385 en 1991 y 469 en 1995 (Ariza, 2004). 
sencia de la peste porcina, el gobierno haitiano decidió eliminar al ganado porcino del país (Pascual Morán y Figueroa, 2005). Esa medida acentuó la pobreza en las zonas rurales ya que en Haití, la pequeña ganadería, en particular de cerdos, representa una parte clave de la economía rural en tanto ha constituido una de las formas más comunes del ahorro en esas zonas y una estrategia de diversificación de riesgos entre los campesinos.

Figura 2: Distribución porcentual de la población ocupada por sector de actividad de 1960 a 2015, República Dominicana ${ }^{\mathrm{a}}$

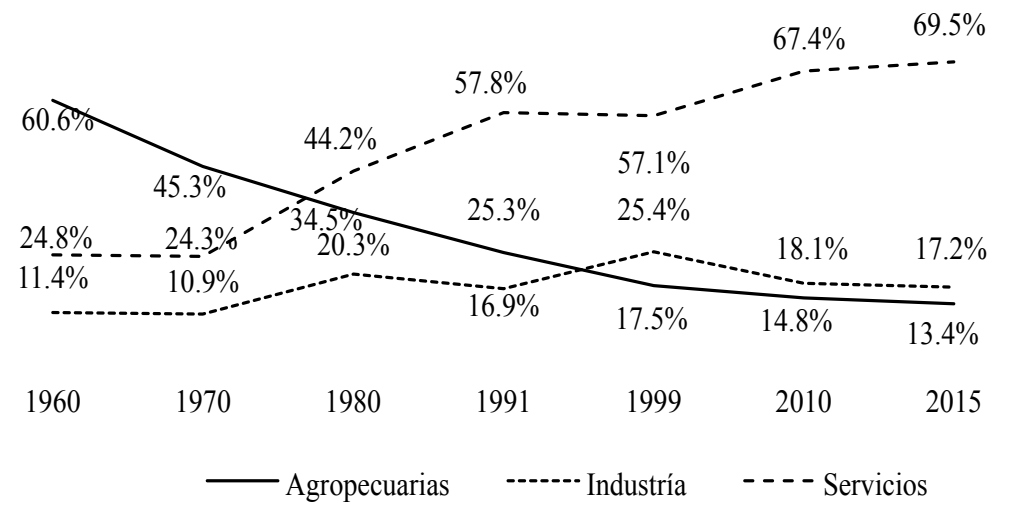

${ }^{a}$ Lo que se observa en esta gráfica es que, entre 1960 y 2015, se invirtió la estructura de ocupación de la mano de obra de tal forma que las actividades agropecuarias pierdan significativamente de su importancia, mientras que el sector de los servicios aumentó la proporción de trabajadores que capta, pasando a ser el principal empleador de la población.

Nota: No se muestran los valores de "no especificados" aunque sí son tomados en cuenta para el cálculo de los porcentajes Fuente: Tejada, 2001, con fuentes combinadas. Los datos para 2010 y 2015 son cálculos propios con datos de la Encuesta Nacional de Fuerza de Trabajo (ENFT).

En el plano político, en 1986, la caída de la dictadura de los Duvalier y el movimiento de dechoukaj ${ }^{19}$ que lo siguió empeoraron la situación económica del país. La difícil "transición democrática" que siguió a la dictadura se detuvo abruptamente con el golpe de estado de 1991, agravando una situación económica y social ya muy volátil. Además, entre 1991 y 1994, el bloqueo comercial impuesto contra Haití por la Organización de los Estados Americanos (OEA) y la Organización de las Naciones Unidas (ONU) para presionar a los golpistas afectó enormemente la economía del país destruyendo miles de puestos de trabajo, especialmente, en el sector

\footnotetext{
${ }^{19}$ Palabra del creole haitiano para designar destrucciones ocasionadas por manifestantes, después de la caída de la dictadura de los Duvalier, de todo lo relacionado a este régimen, incluso obras públicas, empresas o bienes privados cuyos propietarios estaban ligados a la dictadura. El término se usa también para referirse a los mismos actos, generalmente perpetrados a la caída, por la fuerza, de otros gobiernos.
} 
de las maquiladoras. ${ }^{20}$ Durante el periodo del bloqueo comercial, los inversionistas de este sector trasladaron las plantas de producción establecidas en Haití a República Dominicana, Honduras y Costa Rica, entre otros países (Pascual Morán y Figueroa, 2005), acentuando el desempleo en las zonas urbanas.

Finalmente, la serie de convulsiones políticas y catástrofes naturales que han ocurrido durante las décadas de los noventa y del dos mil, que culminó con el terremoto de enero de 2010 así como el brote de cólera que le siguió y las sucesivas inundaciones provocadas por diferentes huracanes, ha propiciado que una proporción cada vez más mayor de personas busquen salir del país. Una parte de ellas encuentra en República Dominicana una alternativa o bien una ruta menos incierta para otros destinos.

Estos cambios y otros hechos contribuyeron a aumentar el volumen de los migrantes haitianos y a diversificar su perfil. Desde la década de los ochenta, la composición del flujo migratorio y las actividades en las cuales los haitianos en República Dominicana se han incorporado han diversificado haciendo sentir su presencia en mercados urbanos y turísticos (Alexandre, 2012; FLACSO/OIM, 2004; Wooding y Moseley-Williams, 2004). Silié et al. (2002) explican que los trabajadores de la caña han dejado de constituir la mayoría de los trabajadores con relación al total de los que se dedican a actividades tales como construcción, turismo, transporte, artesanías, comercio, y otras ocupaciones.

A raíz de la nueva configuración de las fuerzas impulsadoras de la migración tanto en República Dominicana como en Haití los trabajadores haitianos y los dominico-haitianos salieron en su mayoría de los bateyes, de modo que hoy en día, el predominio rural y la incorporación casi exclusivamente en el sector cañero en esta población son características que pertenecen al pasado (Méroné, 2017). La salida de los bateyes y la diversificación de la inserción laboral tuvieron como efecto una mayor visibilidad de la población de origen haitiano, entre otros. Además, desde principios de los años dos mil, el componente estudiantil cada vez más importante en el flujo acarrea a los migrantes haitianos a espacios sociales e institucionales en los que eran ausentes antes. Estos cambios han planteado desafíos enormes para el resto de la sociedad dominicana que, en su mayoría y por razones históricas, políticas e ideológicas, ha sido tradicionalmente desconfiada frente a la migración haitiana (Price Mars, 1953; Moya Pons, 1992). Pues, esta migración no surgió ni se ha mantenido con base en ne-

\footnotetext{
${ }^{20}$ Mientras que, en 1980, las maquiladoras empleaban 80 mil personas, en 1994 sólo existían 400 empleos en el sector. En 2000, el número de empleos generados por las maquiladoras pasaron a 20 mil (Pascual Morán y Figueroa, 2005).
} 
cesidades percibidas desde la sociedad sino, hasta los años ochenta, fue motivada casi exclusivamente por intereses económicos y empresariales ajenos a las preocupaciones cotidianas de los ciudadanos, sin soslayar las causas propias de país de origen.

En la actualidad, y especialmente desde el fin de los acuerdos para la contratación de braceros haitianos a mitad de los ochenta, el flujo migratorio ha salido casi por completo del control de las autoridades y de los actores no estatales tradicionales (empresas, redes de traficantes, agencias de viaje y demás). En efecto, la migración ha madurado y se autosustenta apoyándose no solamente en la dinámica laboral sino también en otros factores relativamente nuevos. Por ejemplo, durante las últimas décadas, la coyuntura sociopolítica en Haití, la crisis ambiental, los periodos de inicios de año académico en República Dominicana así como episodios antihaitianistas (acusaciones, amenazas, actos o medidas en contra de la población de origen haitiano) ${ }^{21}$ se han constituido como causas subyacentes a la fluctuación de la migración.

Las medidas tradicionales de las autoridades dominicanas, a saber, las expulsiones masivas, además de violentar los derechos de las personas, no han ordenado el flujo migratorio, tampoco han mejorado las condiciones en que se desarrollan las actividades de los haitianos en el país. Otras medidas más recientes como la eliminación de la nacionalidad dominicana a miles de dominico-haitianos en 2013 (Perdomo Cordero, 2016) o el Plan Nacional de Regularización de Extranjeros (2014-2015) tampoco reforzaron el protagonismo del estado en el curso de la migración ni permitir a la sociedad de superar los retos que se le plantean. Así, sigue habiendo un terreno fértil para la exacerbación de conflictos históricos, prejuicios mutuos, así como la manipulación política e ideológica. Es en este contexto global que se puede entender de forma amplia los acontecimientos desafortunados que han marcado la migración haitiana en los años recientes y que, a veces, aparecen en los medios de comunicación internacionales.

\section{REFLEXIONES FINALES}

Este articulo muestra como los migrantes haitianos y sus hijos han acompañado el desarrollo de la industria azucarera y las transformaciones económicas en República Dominicana a lo largo del siglo pasado y durante el

\footnotetext{
${ }^{21}$ A veces, las amenazas o medidas surgen de la iniciativa de un grupo de ciudadanos como era el caso en marzo de 2018 en la provincia fronteriza de Pedernales (Ver artículo del diario Listín Diario en https:/www.listindiario.com/la-republica/2018/03/13/506273/haitianos-huyen-atemorizados-de-pedernales). Para otros casos emblemáticos ocurridos en las últimas décadas, consulta Lozano (2005).
} 
inicio del presente; esto, a pesar de las vicisitudes que han experimentado en ese país. Desde que distintas circunstancias acabaron con la migración de los trabajadores cocolos, los haitianos, y luego sus hijos nacidos en República Dominicana, han constituido una mano de obra indispensable para la industria azucarera del país. La mano de obra de origen haitiano también ha sido importante durante la crisis de la agricultura dominicana de los años setenta y ochenta, fungiendo como reemplazante de trabajadores dominicanos que abandonaron los campos para migrar forma interna o internacionalmente. Asimismo, han jugado un papel valioso durante el proceso de tercerización de la economía. Hoy en día, diversos segmentos de la economía rural y urbana compiten entre sí para atraer estos trabajadores, ya que constituye una fuerza de trabajo flexible con características que la vuelve sumisa -inmigrante irregular, posibilidad de contratación no regulada, aceptación de baja remuneración y ausencia de prestaciones sociales - y que existe cierto grado de escasez de mano de obra nativa en algunos sectores (Duarte y Hasbún, 2011; Lozano, 2005).

Las repetidas crisis que se originan de esta migración resultan no solo de factores asociados al mercado laboral sino también de factores fuera de él como pueden ser la condición de irregularidad en la que se encuentra la mayor parte de los inmigrantes haitianos, las diferencias socioculturales con el resto de la población de República Dominicana, los prejuicios y desconocimiento mutuos, la actitud de los dos estados, entre otros. Por su parte, a los hijos de los inmigrantes nacidos en República Dominicana (los dominico-haitianos) las autoridades de este país les han negado la nacionalidad, ${ }^{22}$ lo cual limita significativamente sus posibilidades de integración en diferentes espacios sociales y genera fuertes frustraciones que, en ocasiones, exacerban los prejuicios ya existentes. Ante esta situación, hoy, tal vez más que antes, es imperioso que los estados desarrollen mecanismos que busquen organizar la migración, regularizar la situación de los migrantes, solucionar el problema de los hijos de haitianos nacidos en República Dominicana, entre tantos otros pendientes. Pero más allá de la acción de los estados, es importante que los actores sociales de los dos lados de la frontera - la academia, las asociaciones civiles, los medios de comunicación, las iglesias - participen en el fomento de un mayor conocimiento del otro y la creación de una cultura de tolerancia entre los dos pueblos que comparten la isla La Española.

${ }^{22}$ La muy conocida sentencia TC/0168/13 del Tribunal Constitucional dominicano del 23 de septiembre de 2013 por la que se niego la nacionalidad dominicana a los hijos de inmigrantes en situación de irregularidad - la gran mayoría hijos de inmigrantes haitianos - constituye solo el clímax de un proceso que existió desde décadas atrás. 


\section{REFERENCIAS BIBLIOGRÁFICAS}

Alexandre, Guy, 2012, "Hacia una administración ordenada de la migración entre Haití y República Dominicana", en Vega, Gustavo C. y Carlos Alba V. (coords.) (2012). Haití-México. Hacia una nueva política de cooperación. México, El Colegio de México, pp. 167-188.

Ariza, Marina, 2004, “Obreras, sirvientas y prostitutas. Globalización, familia y mercado de trabajo en República Dominicana", Estudios Sociológicos, vol. 22, núm. 1, pp. 123-149.

Báez, Franc, 1986, Braceros haitianos en la República Dominicana, Editora Taller, Santo Domingo.

Báez, Franc y Lozano, Wilfredo, 1985, Migración internacional y economía cafetalera. Estudio sobre la migración estacional de trabajadores haitianos a la cosecha cafetalera en República Dominicana, Taina, Santo Domingo.

Baud, Michel, 1993, "Una frontera-refugio: dominicanos y haitianos contra el estado (1870-1930)" Estudios sociales, vol. 26, núm. 92, pp. 39-64.

Castillo, José del, 2005, La formación de la industria azucarera dominicana entre 1872 y 1930 Discurso de ingreso como miembro de número de la Academia Dominicana de la Historia, 31 de enero del 2005.

Castillo, José del, 1978, La inmigración de braceros en la República Dominicana, 1900-1930, Cuadernos del CENDIA, vol. 262, núm. 7, Universidad Autónoma de Santo Domingo (UASD), Santo Domingo.

Castor, Suzy, 1983, Migración y relaciones internacionales (el caso haitiano-dominicano), Universidad Nacional Autónoma de México (UNAM), México.

Castor, Suzy, 1971, La ocupación norteamericana de Haití y sus consecuencias (1915-1934), Siglo veintiuno editores, México.

Corten, André, 1971, "Migraciones e intereses de clases" en Pierre-Charles, Gérard, Política y Sociología en Haití y la República Dominicana. Coloquio Dominicano-haitiano de Ciencias Sociales, Universidad Nacional Autónoma de México (UNAM), México.

Cuello, José Israel H., 1997, Contratación de mano de obra haitiana destinada a la industria azucarera dominicana, 1952-1986, Edición Taller, Santo Domingo.

Derby, Robin L.H. y Turits, Richard, 1993, "Historias de terror y los terrores de la historia: la masacre haitiana de 1937 en la República Dominicana", Estudios sociales, vol. 26, núm. 92, pp. 65-76.

Domenach, Hervé, 1986, "Les migrations intra-caribéennes" Revue européenne des migrations internationales, vol. 2, núm. 2, pp. 9-24.

Duarte, Isis y Hasbún, Julia, 2011, "Mano de obra haitiana en la construcción: Características, valoraciones y prácticas" en Duarte et al., Movimientos desde y hacia República Dominicana, Tomo I. Secretaria de Economía, Planificación y Desarrollo, Santo Domingo, pp. 43-105. 
FLACSO/OIM, 2004, Encuesta sobre los inmigrantes haitianos en República Dominicana, Facultad Latinoamericana de Ciencias Sociales, Organización Internacional para las Migraciones, Santo Domingo.

Gaillard, Roger, 1981, Les Blancs débarquent, 1916-1917. La République autoritaire. Imprimerie Le Natal, Puerto Principe.

García Muñiz, Humberto, 2005, “La plantación que no se repite: las historias azucareras de la República Dominicana y Puerto Rico, 1970-1930”, en Revista de Indias, vol. 65, núm. 233, pp. 173-192.

Lozano, Wilfredo, 2005, La paradoja de las migraciones. El Estado dominicano frente a la inmigración haitiana, Editorial UNIBE/FLACSO/SJRM, Santo Domingo.

Lozano, Wilfredo, 1998, Jornaleros e inmigrantes, FLACSO-INTEC, Santo Domingo.

Lozano, Wilfredo y Báez, Franc, 2011, "Politiques migratoires de la globalisation. Le cas de la migration haïtienne en République Dominicaine " en Corten, André, L'Etat faible. Haïti et la République Dominicaine. Mémoire d'encrier, Montréal, pp. 303-318.

Manigat, Lesly François, 1997, Les relations haïtiano-dominicaines, ce que tout Haïtien devrait savoir, Les Cahiers du CHUDAC, Port-au-Prince.

Manigat, Sabine, 2012, “L'immigration haïtienne dans la Carabe. Mythes et réalités des migrations haïtiennes dans la Caraïbe", en Atlas-Caraïbe, disponible en https://atlas-caraibe.certic.unicaen.fr/fr/page-250.html. Consultado el 30 de abril de 2017.

Martínez, Samuel, 1999, "From Hidden Hand to Heavy Hand: Sugar, the State, and Migrant Labor in Haiti and the Dominican Republic", in Latin American Research Review, vol. 34, núm. 1, pp. 57-84.

Méroné, Schwarz Coulange, 2017, La integración de la población de origen haitiano en el mercado de trabajo de República Dominicana. Un análisis sociodemográfico. Tesis de doctorado. El Colegio de México, México.

Moral, Paul, 1978, Le paysan haïtien. (Étude sur la vie rurale en Haïti), Éditions Fardin, Collection du Bicentenaire d'Haïti 1804-2004, Port-au-Prince.

Moya Pons, Frank, 1992, "Las tres fronteras: Introducción a la frontera dominicohaitiana", en Lozano, Wilfredo. La cuestión haitiana en Santo Domingo. Migración internacional, desarrollo y relaciones interestatales entre Haití y República Dominicana. Santo Domingo, FLACSO.

Pascual Morán, Vanessa y Figueroa, Delia, 2005, "La porosa frontera y la mano de obra haitiana en la República Dominicana", en Caribbean Studies, vol. 33, núm. 1, pp. 251-280.

Perdomo Cordero, Nassef, 2016, “Análisis crítico de la sentencia TC/0168/13”, en Memorias. Revista Digital de Historia y Arqueología desde el Caribe, vol. 12, núm. 28, 93-135. 
Price Mars, Jean, 1953, La République D'Haïti et la République Dominicaine. Les aspects divers d'un problème d'histoire de géographie et d'ethnologie, Tome I y II, Editions Fardin, Collection du Bicentenaire d'Haïti 1804-2004, Puerto Principe.

Riveros, Natalia, 2014, Estado de la cuestión de la población de los bateyes dominicanos en relación a la documentación, Editora Búho, Santo Domingo.

Rubens, Evaristo, 2010, “En declive. Industria azucarera RD”, en Hoy, disponible en http: //hoy.com.do/en-decliveindustria-azucarera-rd/. Consultado el 8 de mayo de 2017.

Santamaría, Antonio García, 1995, La industria azucarera y la economía cubana durante los años veinte y treinta. La crisis del sector exportador, comercial y azucarero y su incidencia en la sociedad y en la economía insular, Tesis doctoral. Universidad Complutense, Madrid.

Silié, Ruben et al., 2002, La nueva inmigración haitiana a RD, FLACSO-República Dominicana, Santo Domingo.

Tejada, Argelia Yangüela, 2001, Bateyes del Estado. Encuesta socioeconómica $y$ de salud de la población materno-infantil de los Bateyes Agrícolas del CEA, diciembre 1999, USAID, Santo Domingo.

Turits, R. L., 2014, "Un mundo destruido, una nación impuesta: La masacre haitiana de 1937 en la República Dominicana", Hispanic American Historical Review, vol. 82, núm. 3, pp. 589-635.

Vega, Bernado, 1988, Trujillo y Haití, vol. 1. Fundación Cultural Dominicana, Santo Domingo.

Vega, Bernado, 1983, Haití y la República Dominicana. (1930-1937), vol. I, Fundación Cultural Dominicana, Santo Domingo.

Wooding, Bridget y Moseley-Williams, Richard, 2004, Inmigrantes haitianos y dominicanos de ascendencia haitiana en la República Dominicana, Cooperación Internacional para el Desarrollo and Servicio Jesuita a Refugiados y Migrantes, Santo Domingo.

\section{RESUMEN CURRICULAR DEL AUTOR}

\section{Schwarz Coulange Méroné}

Es doctor en Estudios de Población por el Colegio de México y Maestro en Población y Desarrollo por el Centro de Estudios en Población y Desarrollo (Centre d'Etudes en Population et Développement) de la Universidad Estatal de Haití (Université d'Etat d'Haïti). Tiene una línea de investigación sobre migración y mercado laboral. En específico, investiga la integración de las poblaciones de origen extranjero en el mercado laboral de países de recepción. Ha investigado la integración laboral de los inmi- 
grantes haitianos y sus descendientes en el mercado laboral de República Dominicana, también está interesado y la integración laboral de inmigrantes internacionales en el Zona Metropolitana de la Ciudad de México, así como la segregación laboral de afro-mexicanos e indígenas en el mercado de trabajo en tres estados mexicanos: Guerrero, Oaxaca y Veracruz. Dirección electrónica: scmerone@colmex.mx

Artículo recibido el 8 de mayo de 2017 y aprobado el 21 de mayo de 2018. 